\title{
Multi-phase Al-Fe alloys with layer structure: synthesis and properties
}

\author{
A. B. Shubin*, Yu. V. Kontsevoi, A. G. Meilakh, P. V. Kotenkov, I. S. Sipatov, \\ E. A. Pastukhov
}

Institute of Metallurgy, Ural Branch of RAS, 101 Amundsen St., Ekaterinburg, 620016, Russian Federation

Received 5 April 2016, received in revised form 29 June 2016, accepted 9 August 2016

\begin{abstract}
Metallic alloys can form multi-layer structures during the process of their synthesis. Such structures can be synthesized by direct components interaction, electrolytic deposition, magnetron sputtering, etc. The work to be presented describes the production of multi-phase structures of Al-Fe binary system in the result of two kinds of experiments of direct components interaction. First, the mechanochemical synthesis of alloys from the powders mixtures $(\mathrm{Al}+\mathrm{Fe})$ was carried out. Second, the direct interaction between solid Fe and liquid $\mathrm{Al}$ was performed. In spite of the methods difference, similar structures of alloys were obtained. Typically, the $\mathrm{Al}_{5} \mathrm{Fe}_{2}$ phase is formed as an intermetallic layer on the surface of Fe substrate or Fe powder particles. The core-shell structure is obtained in both the powder particles and Fe rods in a short time interval due to the intensive reactive diffusion of $\mathrm{Al}$ into $\mathrm{Fe}$.
\end{abstract}

K e y w or d s: aluminum, iron, alloy, synthesis, multi-phase structure, core-shell structure

\section{Introduction}

Multi-phase Al-Fe alloys and coatings containing intermetallic compounds can show unique physicochemical and mechanical properties as well as high corrosion resistance. These materials are used as intermediate connection pieces for aluminum and steel tubes in the nuclear industry and missile production. Al-Fe layers are good protective coatings for screw gears and conveyor belts in furnaces working at high temperatures. The synthesis of Al-Fe multi-phase alloys is carried out by a direct components interaction in the combinations solid-solid [1-4] or solid-liquid [5], deposition from saturated vapour [6], magnetron sputtering [7], etc. Also, multi-layer alloys can be prepared using non-metallic intermediate media - e.g., molten salts [8] or liquid pastes containing $\mathrm{Al}$ powder $[9]$.

Powders and bulk samples synthesized by direct Al-Fe interaction can show two or more intermetallic compounds (IMC) in metallographic specimens. Compositions and properties of these multi-phase systems, as well as diffusion peculiarities in multi-layer struc- tures, have been partially investigated in the papers [10-13].

Thin multilayer structures (e.g., in Al-Sc binary system) were studied by the authors [14]. The peculiarity of this system was a temporary coexistence of almost all the intermetallics and two-phase regions during the process of the mutual diffusion of the initial thin Sc layer and the Al substrate. The Sc coating on $\mathrm{Al}$ was obtained by the electrolytic deposition from the molten salt containing Sc. Also, the coreshell inner structures of the IMC particles were studied [15]. The multi-layer structures mentioned above can be prepared using special small additions (like $\mathrm{Ti}$ in Al-Sc alloys).

Here, the authors investigated the mechanochemical synthesis of multi-layer Al-Fe powders produced by the two experimental techniques. The procedure included low-frequency oscillations of the initial powder mixture (Al, Fe) with simultaneous induction heating. Besides, separately (as the model experiment) the direct interaction in the system (solid Fe - liquid $\mathrm{Al}$ ) was studied to observe the formed IMC sequences and to compare them with those obtained in oscilla-

\footnotetext{
*Corresponding author: fax: +7 34326791 86; e-mail address: abshubin@gmail.com
} 
tion cladding procedure for the Al-Fe powder system. Al-Fe intermetallic powders with the specific core-shell structure can be used for a synthesis of composite materials with the copper matrix. One can assume that such composites show high mechanical and tribological properties mainly due to the Al-Fe-Cu sintering.

The next considered question was how similar structures could be produced by the two methods: simple direct interaction in (solid $\mathrm{Fe}$ - liquid $\mathrm{Al}$ ) system and the mechanochemical interaction of powder particles (Fe, Al, after short final heating). The microstructure characterization of synthesized particles was mainly carried out by SEM.

\section{Experimental}

Mechanochemical treatment of powders was carried out as follows. The $\mathrm{Al}$ and $\mathrm{Fe}$ mixture was filled into the special cylindrical steel container. The spherical powder particles were between $1-100 \mu \mathrm{m}$ in diameter. Typically, the diameter of Fe particles was much larger than that of $\mathrm{Al}$ ones. The container was filled with the protective atmosphere (nitrogen or argon) and subjected to longitudinal oscillating movement with an amplitude of $10 \mathrm{~mm}$ and a frequency of 30-50 $\mathrm{Hz}$. The height and inner diameter of the container named as cladder were $200-250 \mathrm{~mm}$ and $20-30 \mathrm{~mm}$, respectively.

The powder mixture movement under these conditions can be described by equations described in [16]. In fact, the powder mixture was subjected to reciprocating movement, but the frequency and other characteristics of oscillations were essentially different for cladder itself and (Fe, $\mathrm{Al}$ ) powders. Due to the difference in movement speed and oscillation phase, the $\mathrm{Al}$ and $\mathrm{Fe}$ particles contact each other both by side and direct collisions. It was expected that sliding collisions cause the coating of more hard Fe particles by comparatively soft $\mathrm{Al}$ ones due to tangential tensions. The direct mutual hits cause local plastic deformations, and the diffusion processes are intensified.

After 3-5 min of the mechanical treatment the powder mixture was heated by the inductor concentrically encompassing the container. Cladder oscillation was not interrupted during heat treatment to avoid particles agglomeration and sintering. The heating temperature was set in the range of $720-900^{\circ} \mathrm{C}$; the exposure time at the defined temperature was about $20-30 \mathrm{~s}$. In this way, the Al-Fe alloy powders containing intermetallic compounds were produced for further using as the premix for composite synthesis.

Besides, the special experiments including the direct interaction of liquid $\mathrm{Al}$ and solid $\mathrm{Fe}$ were performed. Metallic Al of $95-100 \mathrm{~g}$ was melted in alumina crucibles heated to the predefined temperature within the interval $\left(720-900^{\circ} \mathrm{C}\right)$ in air. After the procedure, the crucible was pulled out of a shaft furnace and set on a fireclay stand. Simultaneously a cylindric Fe rod of $2-3 \mathrm{~mm}$ in diameter was inserted into $\mathrm{Al}$ melt in the crucible. It was observed that all the liquid Al solidified in 30-60 s depending on the initial temperature. It was found that this time was enough to form intermetallic layers on a rod surface. Further, the character of intermetallics formation in both considered processes (powder mechanochemical synthesis with heating and "macroscopic" direct Al-Fe interaction) was investigated and compared.

Microstructure investigations were performed using Carl Zeiss EVO 40 scanning electron microscope equipped by Oxford Instruments INCA X-Act EDX detector. XRD studies were carried out using Shimadzu XRD 7000C diffractometer.

\section{Results and discussion}

The aim of the synthesis of layered powder particles consists of obtaining the specific core-shell structure including $\mathrm{Fe}$ core and intermetallic coating on its surface. To realize such a synthesis, the procedure described above was used. The $\mathrm{Al}$ powder (spherical particles of $1-5 \mu \mathrm{m}$ in size) was intensively mixed with the Fe powder spherical particles (about $40-100 \mu \mathrm{m}$ in diameter). In consequence, spherical Fe particles plated by the layer of small $\mathrm{Al}$ particles were obtained. Melting of $\mathrm{Al}$ particles coating and further chemical interaction between coating and substrate was caused by short-time heating. A part of $\mathrm{Al}$ spheres interacted with the Fe substrate and intermetallic layer was formed. Another part does not react due to short-time thermal treatment and settles on Fe particles surface (Fig. 1a). The image of typical interacted particle is shown in Fig. 1b.

As the result of phases compositions determination by SEM-EDX method (Fig. 1b) it was shown that the particle core (light field) is pure Fe; the composition of the shell (grey field around the core) is varied for different particles within the interval (at.\%): Fe - 23.0-30.0; $\mathrm{Al}$ - the balance. The lower limit of the composition meets the homogeneity region of $\mathrm{Al}_{3} \mathrm{Fe}$ intermetallic phase [17]. The upper limit closely corresponds to the $\mathrm{Al}_{5} \mathrm{Fe}_{2}$ IMC.

It was demonstrated by macroscopic modeling of Fe-Al pair interaction that the exposure time of 20-30 $\mathrm{s}$ was enough to synthesize well-formed intermetallic coating on the Fe rod surface. The results of the interaction of $\mathrm{Al}$ bath with the Fe rod for different temperatures are shown in Fig. 2a,b. One can see three contrast fields on the intersection images: dark - Al, gray - intermetallic compound, and light - metallic Fe.

One can observe the similar character of Al-Fe in- 

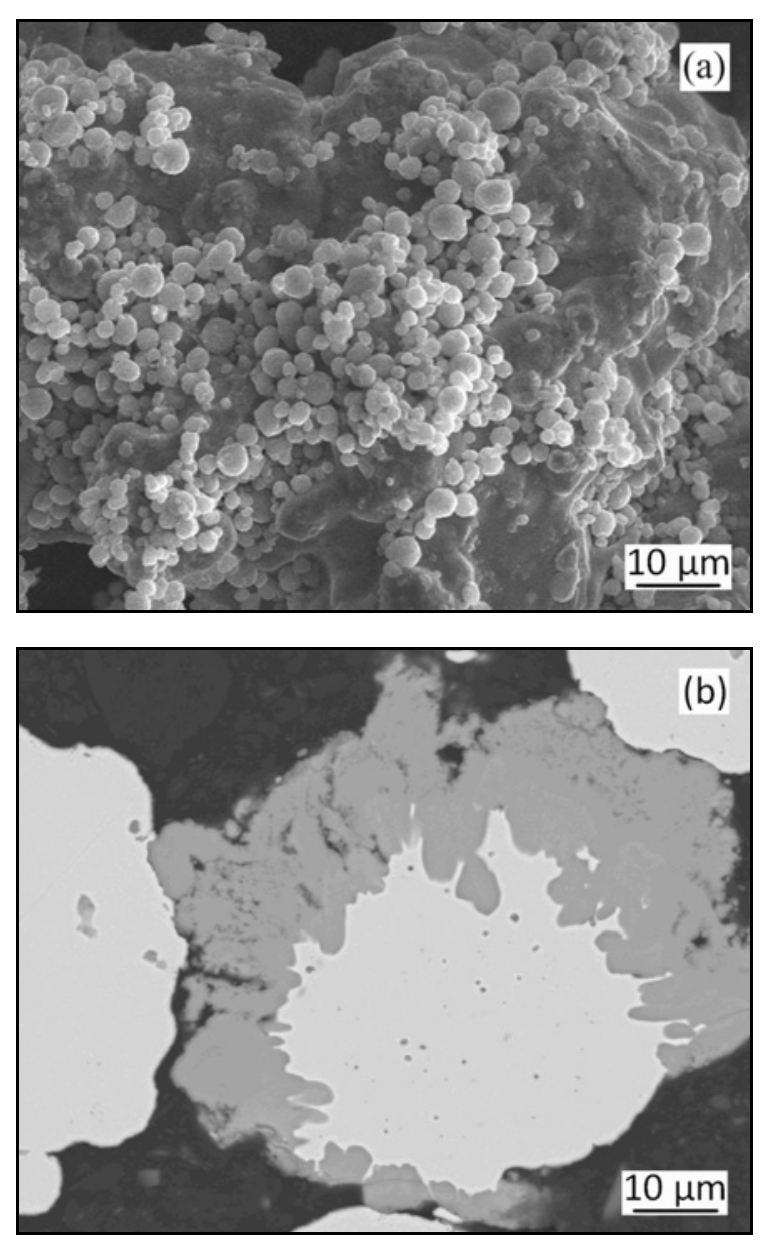

Fig. 1. SEM images of: (a) residual aluminum particles on the surface of multi-layer intermetallic particle observed by SE detector; (b) cross-section of IMC particle observed by BSE detector.

teraction for lower and upper limits of temperature interval under consideration $\left(720-900^{\circ} \mathrm{C}\right)$. The peculiarities of IMC growth are also similar, but the thickness of the intermetallic layer is increased at a higher temperature (Fig. 2b). The composition of IMC layers on the iron rod surface was measured by the standard SEM-EDX method (at.\%): Fe - 28.4; Al - the balance. The components composition meets the $\mathrm{Al}_{5} \mathrm{Fe}_{2}$ IMC taking into account the homogeneity region. This composition is almost equal for all tested points of the intermetallic layers in both samples. The $\mathrm{Al}_{3} \mathrm{Fe}$ intermetallic compound was not observed in this case. The IMC layer corresponding to the image in Fig. 2a at higher magnification is shown in Fig. 3. One can see that reactive diffusion occurs mainly from $\mathrm{Al}$ into the Fe sample, but some amount of $\mathrm{Fe}$ penetrates into $\mathrm{Al}$ matrix, and the intermetallic compounds are formed in grain boundaries during the $\mathrm{Al}$ solidification.

The interaction in "macroscopic" Al-Fe system (Figs. 2, 3) is similar for different initial temperatures
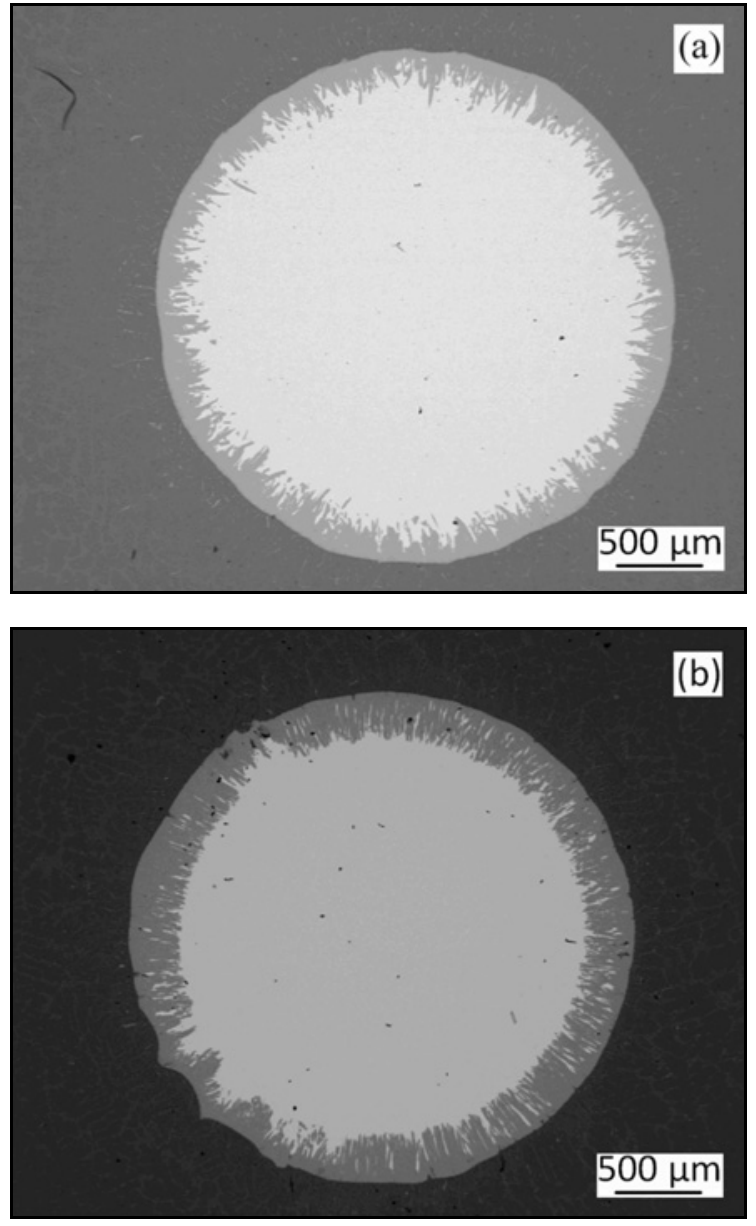

Fig. 2. SEM images observed by BSE detector show interaction between $\mathrm{Fe}$ rod and liquid $\mathrm{Al}$ after (a) 10-20 s at $720^{\circ} \mathrm{C}$ and (b) $20-30 \mathrm{~s}$ at $900^{\circ} \mathrm{C}$.

of liquid $\mathrm{Al}$ and leads to the formation of the $\mathrm{Al}_{5} \mathrm{Fe}_{2}$ coating on the surface of Fe sample. It is known that comparatively long exposure time of the solid Fe in liquid $\mathrm{Al}$ can lead to the formation of two-phase layers containing the $\mathrm{Al}_{5} \mathrm{Fe}_{2}$ and $\mathrm{Al}_{3} \mathrm{Fe}$ intermetallics [5, 18]. Direct interaction between solid Fe and liquid $\mathrm{Al}$ the $\mathrm{Al}_{3} \mathrm{Fe}$ phase was not detected by the SEM-EDX method in all the samples.

Considering the plating of $\mathrm{Fe}$ by the $\mathrm{Al}$ in a powder mixture (like described above) one can see that the quantity and composition of the synthesized IMC depend on the process conditions, particle size ratio, etc. The main aim of plating is the formation of coreshell structure similar to shown above in Fig. 1b. The inner structure of plated particles was analyzed. It was found that there were fully plated particles with coreshell structure and partially coated ones. Some portion of Al-Fe alloy particles forming quite interesting structures due to complicated interaction character was found. The particles with discontinuous $\mathrm{Al}_{5} \mathrm{Fe}_{2}$ layers (gray fields) are shown in Fig. 4. 


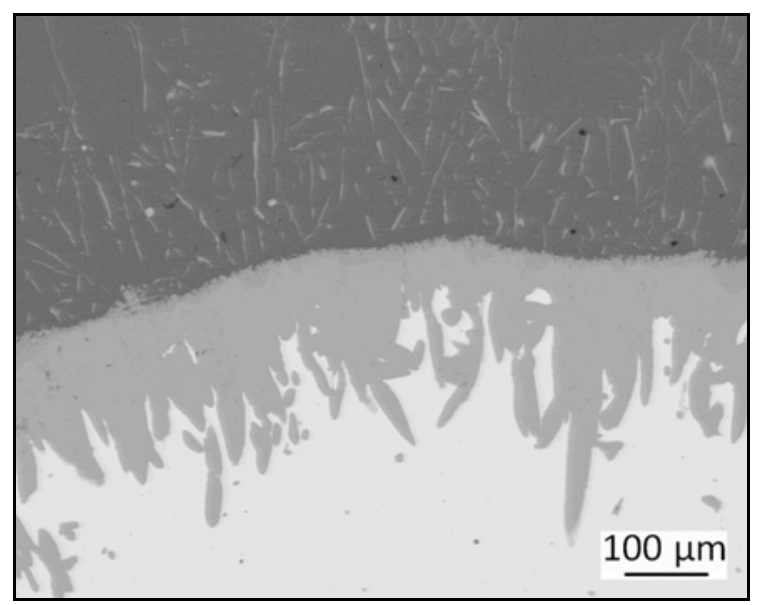

Fig. 3. SEM image of sample using BSE detector shows the interaction between iron rod and aluminum bath during the Al solidification; solid-liquid contact duration was 10$20 \mathrm{~s}$ (estimation), the initial liquid aluminum temperature $720^{\circ} \mathrm{C}$. The $\mathrm{Al}_{5} \mathrm{Fe}_{2}$ phase is imaged by gray strips on light background - in Fe sample; gray strips on dark background - in Al matrix.

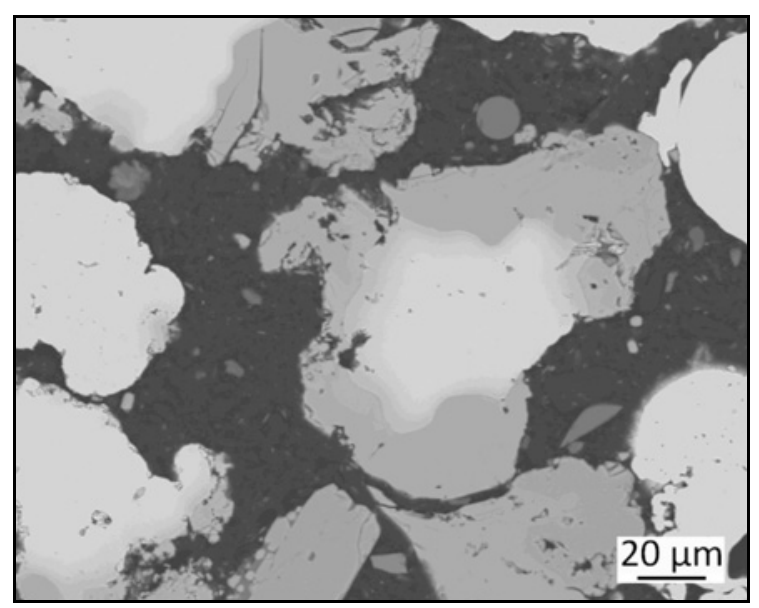

Fig. 4. SEM image observed using BSE detector of $\mathrm{Al}_{5} \mathrm{Fe}_{2}$ particles of non-uniform morphology obtained by synthesis of mechanochemical and thermal treatment of initial powders.

Rarely, some particles consist of all the intermetallics and two-phase regions known for Al-Fe phase diagram. All these regions are well seen in the metallographic section (Fig. 5a). The linear EDX scanning (Fig. 5b) shows the relative intensities of $\mathrm{Fe}$ and $\mathrm{Al}$ spectra along the direct scanning line shown in Fig. $5 \mathrm{a}$. The sequence of numeric Fe concentration values along the EDX scanning line for all the contrast layers (from the darkest to the lightest) is the following (at.\%, $\mathrm{Al}$ - the balance): $31.0 ; 34.1 ; 39.0 ; 49.2 ; 77.7 ; 100$.

The typical result of the XRD-analysis for synthesized Al-cladded Fe powders is presented in Fig. 6.
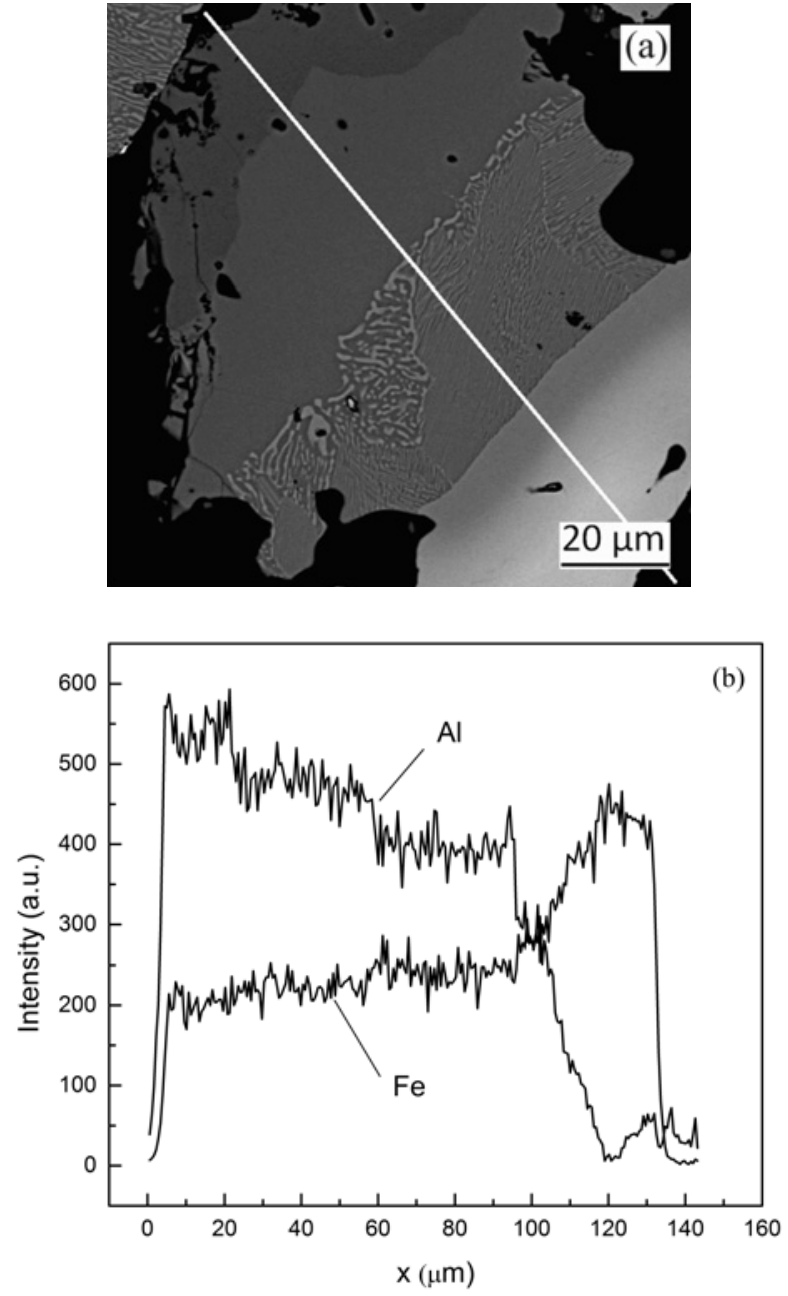

Fig. 5. (a) Multi-layer particle of Al-Fe powder imaged by SEM using BSE detector; (b) Intensities distribution of $\mathrm{Al}$ and $\mathrm{Fe}$ along the line marked in (a) as obtained by EDX.

\section{Conclusions}

Considering the interaction between the liquid metallic $\mathrm{Al}$ and solid Fe under different conditions one can conclude that IMC formation mainly depends on the geometric shape of interacted particles, contact time of $\mathrm{Fe}$ and $\mathrm{Al}$ phases, temperature, and other factors.

Essential similarities take place in components behavior for different "scales" of interaction. One can find some common peculiarities when $\mathrm{Al}$ and Fe interact in particle-particle "microscopic scale" and metals are in contact in rod-bath "macroscopic scale". In both considered cases, there was short-time contact between solid Fe and liquid Al. The "geometry" of experiments was different, but the time of mutual exposure of Al-Fe pair at the predefined temperature (720-900 $\left.{ }^{\circ} \mathrm{C}\right)$ was close for both cases: vibrational cladder and metallic aluminum in a crucible. 


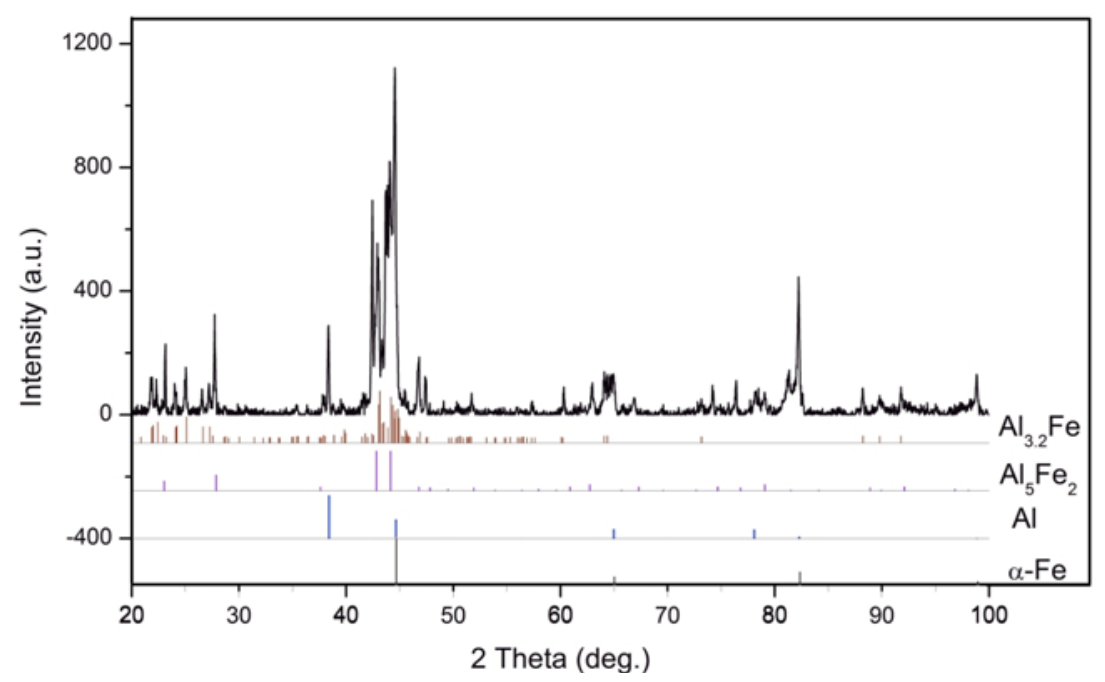

Fig. 6. Diffractogram for a typical mixture of $\mathrm{Al}, \mathrm{Fe}$ and their intermetallic compounds produced in cladding device. The peaks of $\mathrm{Al}_{5} \mathrm{Fe}_{2}$ are well seen. Also, a small quantity of $\mathrm{Al}_{3} \mathrm{Fe}$ phase is present.

It can be seen that the more simple "macroscopic" experiment is a good model of the interaction and reactive diffusion occurring in more complicated "microscopic" one. In both kinds of experiments substantially similar results were obtained. The basic IMC which forms the intermetallic layer in the Al-Fe boundary is an $\mathrm{Al}_{5} \mathrm{Fe}_{2}$ intermetallic phase.

\section{Acknowledgement}

This research was supported by the Russian Science Foundation (Grant 15-13-00029).

\section{References}

[1] Jindal, V., Srivastava, V. C., Das, A., Ghosh, R. N.: Materials Letters, 60, 2006, p. 1758. doi:10.1016/j.matlet.2005.12.013

[2] Huang, B., Ishihara, K. N., Shingu, P. H.: Materials Science and Engineering A, 321, 1997, p. 72. doi:10.1016/S0921-5093(97)00041-5

[3] Springer, H., Kostka, A., Payton, E. J., Raabe, D., Kaysser-Pyzalla, A., Eggeler, G.: Acta Materialia, 59, 2011, p. 1586. doi:10.1016/i.actamat.2010.11.023

[4] Dobromyslov, A. V., Taluts, N. I., Pilyugin, V. P.: Letters on Materials, 4, 2014, p. 253.

[5] Bouayad, A., Gerometta, Ch., Belkebir, A., Ambari, A.: Materials Science and Engineering A, 363, 2003, p. 53. doi:10.1016/S0921-5093(03)00469-6

[6] Fonda, E., Traverse, A.: J. of Magnetism and Magnetic Materials, 268, 2004, p. 292. doi:10.1016/S0304-8853(03)00537-7
[7] Sanchette, F., Billard, A.: Surface and Coatings Technology, 142-144, 2001, p. 218. doi:10.1016/S0257-8972(01)01197-5

[8] Ilyshenko, N. G., Anfinogenov, A. I., Shurow, N. I.: Interaction of Metals in Ion Melts. Moscow, Nauka 1991 (in Russian).

[9] Murakami, K., Nishida, N., Osamura, K., Tomota, Y., Suzuki, T.: Acta Materialia, 52, 2004, p. 2173. doi:10.1016/i.actamat.2004.01.009

[10] Kajihara, M.: Materials Transactions, 47, 2006, p. 1480. doi: $10.2320 /$ matertrans. 47.1480

[11] Cui, Y.-W., Kato, R., Omori, T., Ohnuma, I., Oikawa, K., Kainumac, R., Ishida, K.: Scripta Materialia, 62, 2010, p. 171. doi:10.1016/j.scriptamat.2009.10.011

[12] Kobayashi, S., Yakou, T.: Materials Science and Engineering A, 338, 2002, p. 44. doi:10.1016/S0921-5093(02)00053-9

[13] Bhanumurthy, K., Krauss, W., Konys, J.: Fusion Science and Technology, 65, 2014, p. 262. doi:10.13182/FST13-651

[14] Shubin, A. B., Shunyaev, K. Yu., Yamshchikov, L. F.: Defect and Diffusion Forum, 312-315, 2011, p. 211.

[15] Shubin, A. B., Popova, E. A., Shunyaev, K. Yu., Pastukhov, E. A.: Russian Metallurgy (Metally), 2010, 2010 , p. 740 .

doi:10.4028/www.scientific.net/DDF.312-315.211

[16] Kontsevoi, Y. V., Pastukhov, E. A., Ignatev, I. E., Bulanov, V. Y., Ignateva, E. V.: Russian Journal of Non-Ferrous Metals, 50, 2009, p. 507. doi:10.3103/S1067821209050137

[17] Sundman, B., Ohnuma, I., Dupin, N., Kattner, U. R., Fries, S. G.: Acta Materialia, 57, 2009, p. 2896. doi:10.1016/j.actamat.2009.02.046

[18] Takata, N., Nishimoto, M., Kobayashi, S., Takeyama, M.: Intermetallics, 54, 2014, p. 136. doi:10.1016/i.intermet.2014.06.003 